\title{
Past Editor Series \\ The social transformation of Singapore medicine through 55 years of the SMJ
}

Ee Heok $\underline{K u a}^{1}, \mathrm{MD}$, FRCPsych, Jade Phek Hui ${\underline{K u a^{2}}}^{,}$MRCS A\&E, FAMS

\begin{abstract}
The Singapore Medical Journal (SMJ) has in the past 55 years reflected the phenomenal socioeconomic progress of Singapore. Publications in the pre-independent years were mainly on diseases like cholera, diphtheria, leprosy, tetanus and worm infestation. In the new millennium, the research papers included molecular genetics, health economics, obesity, Internet medicine, cancer, cosmetic surgery and palliative medicine. The annual SMA Lecture published in the SMJ provides an ethical compass for doctors to remind them of primum non nocere.
\end{abstract}

Keywords: history, Singapore medicine, SMJ

\section{INTRODUCTION}

The portrait of an era which witnessed the emergence of Singapore from Third to First World is often framed by a narrative of dramatic progress, from a colonial outpost in the backwater to a metropolis with a skyline of towering buildings stabbing the sky. In a quiet and measured way, this transformation is also chronicled in the Singapore Medical Journal (SM), which has charted medical advances in tandem with Singapore's socioeconomic development in the past 55 years. The published papers defined these changes and have become milestones that acquired a sepia tone with the march of time.

\section{SMJ THROUGH THE PAST 55 YEARS}

In the early 1960s, with the insalubrious state of public health, SMJ papers were focused mainly on tetanus, cholera, leprosy, tuberculosis, gonorrhoea, syphilis, diphtheria, malaria and worm infestation. Professor Tow SH published his seminal work on choriocarcinoma in 1965, ${ }^{(1)}$ and Dr Gwee Ah Leng headed the medical team during the koro epidemic of 1969. ${ }^{(2)}$ In the 1970s, there were publications on social problems like opium addiction, ${ }^{(3)}$ heroin abuse, ${ }^{(4)}$ smoking ${ }^{(5)}$ and alcoholism. ${ }^{(6)}$ Military doctors wrote on the health of national servicemen. ${ }^{(7)}$

However, in the 1980s, the published work on illness patterns was decidedly different. There were studies on AIDS, ${ }^{(8)}$ anorexia nervosa ${ }^{(9)}$ and work stress. ${ }^{(10)}$ The Hotel New World disaster was reported by Dr Lim Meng Kin and the medical rescue team. ${ }^{(11)}$ In the 1990s, communicable diseases no longer dominated the contents of the $S M$ J; research papers were on the ageing population, ${ }^{(12)}$ escalating health costs, ${ }^{(13)}$ cancer, ${ }^{(14)}$ obesity ${ }^{(15)}$ and doctor's stress. ${ }^{(16)}$ A report on the mental health of the nation was published in 1998, ${ }^{(17)}$ while Dr How J wrote on decompression sickness and the Mass Rapid Transit (MRT), a landmark national development in Singapore. ${ }^{(18)}$
The new millennium heralded changes in the health and social landscapes of Singapore. SM/ papers included molecular genetics, ${ }^{(19)}$ Internet medicine, ${ }^{(20)}$ positron emission tomography scan, ${ }^{(21)}$ liver transplantation, ${ }^{(22)}$ gambling addiction, ${ }^{(23)}$ health economics, ${ }^{(24)}$ palliative medicine, ${ }^{(25)}$ sports medicine, ${ }^{(26)}$ cosmetic surgery ${ }^{(27)}$ and robot-assisted surgery. ${ }^{(28)}$ The SARS epidemic, a tragic event in Singapore's history, was documented by doctors on the front line. ${ }^{(29,30)}$

In 2005, medical education was the focus during the centennial of the National University of Singapore Medical School. A few years earlier in 1998, Professor Tan Chorh Chuan, who was then the dean, published a paper on rethinking medical education. ${ }^{(31)}$ Leading nursing educationists wrote on the new Alice Lee Centre for Nursing Studies ${ }^{(32)}$ and Dr Cheong Pak Yean expatiated on the future of family medicine training. ${ }^{(33)}$

During the 2015 Jubilee year, two papers reflected important societal issues in Singapore - the Mental Capacity Act for the care of the cognitively impaired elderly ${ }^{(34)}$ and polypharmacy in the treatment of elderly patients, especially in nursing homes. ${ }^{(35)}$ The short-lived upheaval in Little India was reported by emergency doctors caring for victims of the riot. ${ }^{(36)}$

\section{THE ETHICAL MIND: SMA LECTURES}

The SMJ publishes the annual Singapore Medical Association (SMA) Lecture, which often highlights prevailing and pressing socio-medical matters. With rising healthcare costs, some doctors have questioned whether healthcare is a commodity to be bought and sold in the marketplace. Corporate terms like 'customers' and 'clients' are now used in hospitals to replace 'patients'. In the 1996 SMA Lecture, Dr Charles Toh cautioned that "economic growth driven by a free market does not necessarily translate into better healthcare for all." (37) Dr Yong Nen Khiong, in the 1993 Lecture, opined: "Good doctoring keeps cost down."(38)

\footnotetext{
${ }^{1}$ Department of Psychological Medicine, National University of Singapore, National University Health System, ${ }^{2}$ Emergency Department, KK Women's and Children's Hospital, Singapore

Correspondence: Prof Kua Ee Heok, SMJ Past Editor (1997-2000), Tan Geok Yin Professor of Psychiatry and Neuroscience, National University of Singapore, and Senior Consultant Psychiatrist, National University Hospital, 1E Kent Ridge Rd, Singapore 119228. ee_heok_kua@nuhs.edu.sg
} 


\section{0-1964}

- Tetanus in Singapore; Gwee AL, December 1960

- Gonorrhoea in school children; Chew PK, March 1961

- Whipworm infestation in children; Wong HB and Tan KH, March 1961

- Ocular complications of leprosy in Singapore; Loh CK and Lim SM, September 1961

- Intestinal parasites in various communities of Singapore island; Desowitz et al, September 1961

- Corynebacterium Diphtheriae in Singapore; Stein J et al, June 1962

- Japanese encephalitis in Singapore children; Phoon WO and Lim KA, March 1963

- Cholera outbreak; Gwee AL, June 1963

- Syphilitic hydrarthrosis; Yeoh KH, September 1963

\section{5-1974}

- Poliomyelitis immunization programme; Lee LH et al, June 1965

- Choriocarcinoma; Tow SH, September 1965

- Soil-transmitted helminths in Singapore; Kleevens JWL, March 1966

- Trachoma in Singapore; Lim SM, September 1966

- Oral contraceptive; Hu SC and Yung SM, December 1966

- Tuberculous meningitis in children; Paul F, June 1967

- Malaria outbreak in Singapore; Chew PK, June 1968

- Pulmonary Tuberculosis - surgical management; Tan NC, December 1968

- Leprosy in Singapore; Khong KY, September 1969

- Koro epidemic; Gwee AL et al, December 1969

- Opium smokers - ventilator capacity; Leong HK, June 1970

- Alcoholism in Singapore; Khoo OT and Fernandez, June 1971

- General paralysis of the insane; Chia BH and Tsoi WF, October 1971

- Suicide in Singapore; Chia BH and Tsoi WF, April 1972

- Neonatal tetanus in Singapore; Chen AJ, June 1973

- Ethics of transplantation and human experimentation: Khoo OT, September 1974

\section{5-1984}

- Carbon monoxide poisoning; Seah HC and Chao TC, September 1975

- Enteric fever surveillance; Koh TS and Goh KT, March 1976

- National service registrants; How J and Leong CC, October 1977

- Dengue haemorrhagic fever outbreaks; Chan KL et al, October 1977

- Heroin abuse in Singapore; Teo SH et al, June 1978

- Smoking in a local community; Ng KS et al, June 1979

- Anorexia nervosa - a clinical and psychosocial study; Ong YL et al, October 1982

\section{5-1994}

- Utilization and expenditure on medical services; Fong NP and Phua KH, April 1985

- Rice gruel in the management of infantile diarrhoea; Wong HB, September 1985

- Terminal care - what the carers think; Merriman A et al, August 1986

- AIDS - the facts; Feng PH, October 1986

- Myopia in ten year old children; Ling SL et al, August 1987

- Hotel New World disaster - medical support; Lim MK et al, April 1988

- The patient's right to know; Quah SR, April 1989

- Work stress and mental distress; Kua EH et al, August 1989

- MRT (Mass Rapid Transit) - decompression sickness; How J et al, December 1990

- Health of elderly Chinese living in the community; Kua EH, April 1990
- Cigarette smoking among school children; Emmanuel SC et al, June 1990

\section{5-2004}

- Information technology in healthcare cost containment; Lun KC, February 1995

- Management of obesity; Cheah JS, June 1996

- Designer drugs - ecstasy; Kua EH, January 1997

- Emergency department complaints; Ooi SBS, March 1997

- Voluntarism; Lyen K, December 1997

- Medicine and the pharmaceutical industry; Tan SY, March 1998

- Mental health of a nation; Fones CSL et al, June 1998

- Rethinking medical education; Tan CC, June 1998

- Doctor under stress; Kua EH, November 1998

- What makes a good doctor; Fones CSL et al, December 1998

- Acupuncture treatment; Yong D et al, April 1999

- National servicemen and adjustment; Cheok CS et al, May 2000

- The Internet in healthcare; Chin R, September 2000

- Medicine in the digital era; Feng PH, November 2000

- Molecular genetics; Teh BT, January 2001

- Stigma of mental illness; Lai YM et al, March 2001

- Traditional Chinese medicine; Ho NK, October 2001

- Doctor-patient relationship - a covenant of trust; Chin JJ, December 2001

- Human patient simulator in teaching medical students; Tan GM et al, May 2002

- SQ 006 crash; Tan SY, June 2002

- Social cost of disease and economics of prevention; Phua KH, July 2002

- The quest for nursing excellence; Ang BC, October 2002

- SARS outbreak: how many reminders do we need? Tambyah PA, April 2003

- SARS - heroes and heroines of the war; Chee YC, May 2003

\section{5-2015}

- Brain differences in bilingualism; Chee M, February 2005

- Positron emission tomography; Ho GCL, June 2005

- Centennial of medical education; Lee YK, August 2005

- Liver transplantation in Singapore; Isaac J and Lim SG, July 2006

- Pursuit of thinness - outcome study of anorexia nervosa: Lim SL et al, March 2007

- Alice Lee Centre for Nursing Studies; O’Brien AP and Arthur DG, October 2007

- Cost of medical education; Ng CL, May 2009

- Resuscitation programmes in the community; Anantharaman V, August 2011

- Palliative homecare nurses; Chong PH and Poon WH, March 2011

- Pathological gamblers; Lee KM et al, June 2011

- Cancer trends in Singapore; Lim GH et al, January 2012

- Sports medicine; Tan B, October 2013

- Family medicine education and training; Cheong PY, March 2014

- Weight management programme; Tan WI and Wong TK, March 2014

- Primary care physicians and their health; Tan NC et al, March 2014

- Cosmetic procedures among youths in Singapore; $\mathrm{Ng} \mathrm{JH}$ et al, August 2014

- Robot-assisted total knee arthroplasty; Liow MH et al, October 2014

- Pharmacist review in nursing homes; Chia HS et al, September 2015

- Mental capacity; Ng PS et al, December 2015

- The little India riot; Lee WF et al, December 2015 
Focusing on the ethical mind, Professor SS Ratnam challenged the medical fraternity in the 1977 Lecture: "I think the time has come when we critically review our own position in relation to society and its needs and to re-dedicate ourselves to our first and only cause as doctors in making our only role that of helping the sick."(39) In the 1999 Lecture, Dr Chew Chin Hin reminded the doctors "not to be ministered unto, but to minister".(40) A few years earlier, in the 1971 Lecture, Dr Yahya Cohen exhorted the SMA to "instil among its adherents a sense of values so necessary to dignified survival - of values such as pride but not arrogance, of discipline but not servility, of respect but not fear, of loyalty but not subservience, and in so doing to imbue the coming generations with a deportment that is both discriminating and courageous" ${ }^{(41)}$ With the restructuring of hospitals and new governance, there was an uneasiness about the role of administrators. Professor Woo Keng Thye, who spoke on doctor leadership at the 2007 Lecture, stressed the need to "walk the ground", invoking the principles of Sun Tzu's Art of War. ${ }^{(42)}$

One of the most inspiring speeches published in the $S M$ / was the SMA Lecture of 1997 by Dr Wong Heck Sing on role models in medicine. ${ }^{(43)}$ He enumerated the attributes of a good mentor: clinical competence; broad perspective of life; well-versed with the art and science of medicine; ability to teach; and making the patient's welfare a priority. His Hall of Famers included Arthur Ransome, Yahya Cohen, Thamboo John Danaraj, Gwee Ah Leng, Lim Kee Jin, Seah Cheng Siang, Wong Hock Boon and K Shanmugaratnam.

\section{FROM THE ARCHIVES}

In the last 55 years, the $S M$ J has recorded the social history of public health and medical advances in Singapore. As you scan through the catalogue of papers culled from the archives (Table I), you will be amazed that some of the diseases that were prevalent in the 1960s are now rarely encountered. There is also a sense of nostalgia reading the papers, especially if you personally know the doctors, some of whom have passed on; these pioneer doctors were able to conduct research with meagre or no grants and write papers, albeit encumbered by heavy daily clinical duties.

\section{CONCLUSION}

The $S M$ / has chronicled the rise of Singapore medicine and the socioeconomic development of this city state. With the ferocity of the pace of life, some publications may have been missed or read and forgotten. There was a gentle reminder by Dr Raj Mohan Nambiar in the 2004 SMA Lecture, when he warned of escalating medical litigation and the surge in insurance premiums. ${ }^{(44)}$ In the 2005 Lecture, Dr Chee Yam Cheng quoted that the insurance premium for cosmetic practice had risen phenomenally from $\$ 5,250$ in 2000 to $\$ 22,875$ in 2005 , and general practice from $\$ 700$ to $\$ 1,740 .{ }^{(45)}$ The emphasis or re-emphasis must be primum non nocere or 'first, do no harm'.

As Singapore medicine evolves and expands, the $S M$ J will continue to reflect this transformation. In the next decade, the publications are unlikely to be on cholera, malnutrition, worm infestation or opium addiction. There may be more publications on health costs, integrated regional health system, translational research and dementia prevention.

A notable change in the authorship of the $S M$ / papers is the increasing number of women authors. In the sixties, there were less than $10 \%$, as compared to nearly $40 \%$ in the last decade; even the authorship of this paper is a fine balance of genders. With the global feminisation of medicine, it is perhaps timely for the SMA - possibly one of the last few bastions of male dominance in Singapore - to consider, in the not-to-distant future, a woman as the SMJ Editor.

The Past Editor Series is a collection of invited articles written by former SMJ Editors and their co-authors, who are respected medical practitioners in their respective field of expertise.

\section{REFERENCES}

1. Tow SH. Choriocarcinoma: a review of current concepts based on the Singapore experience. Singapore Med J 1965; 5:117-26.

2. Gwee AL; Koro Study Team. The Koro "epidemic" in Singapore. Singapore Med J 1969; 10:234-42.

3. Koon LH, Chuan PS, Gandevia B. Ventilatory capacity in a group of opium smokers. Singapore Med J 1970; 11:75-9.

4. Teo SH, Chee KT, Tan CT, Ng BC. Heroin abuse in Singapore - a profile and characteristics study. Singapore Med J 1978; 19:65-70.

5. Lee HP, Ng KS, Chan KH, Liang HL. Smoking in a local community in Singapore. Singapore Med J 1979; 20:323-9.

6. Khoo OT, Fernandez P. The problem of alcoholism in Singapore. Singapore Med J $1971 ; 12: 154-60$.

7. How J, Leong CC. Physique of school boys and school leavers who are NS registrants. Singapore Med J 1977; 18:155-63.

8. Feng PH. AIDS - the facts. Singapore Med J 1986; 27:96-8.

9. Ong YL, Tsoi WF, Cheah JS. A clinical and psychosocial study of seven cases of anorexia nervosa in Singapore. Singapore Med J 1982; 23:255-61.

10. Kua EH, Tian CS, Lai L, Ko SM. Work stress and mental distress. Singapore Med J 1989; 30:343-5.

11. Lim MK, Fong YH, Tan EH, Lee KH. Medical support at the Hotel New World disaster. Singapore Med J 1988; 29:125-9.

12. Kua EH. The health of elderly Chinese living in the community. Singapore Med J 1990; 31:111-5.

13. Goh LG, Cheong PY, Phua KH. Calculating the GP consultation fee in Singapore: towards a rational costing approach. Singapore Med J 1993; 34:496-9.

14. Kong HL. Cancer therapeutics beyond 2000 - more rationality, less empiricism. Singapore Med J 1999; 40:125-7.

15. Cheah JS. Current management of obesity. Singapore Med J 1996; 37: 299-303.

16. Kua EH. Doctor under stress. Singapore Med J 1998; 39:478.

17. Fones CS, Kua EH, Ng TP, Ko SM. Studying the mental health of a nation: a preliminary report on a population survey in Singapore. Singapore Med J 1998; 39:251-5.

18. How J, Vijayan A, Wong TM. Decompression sickness in the Singapore Mass Rapid Transit Project. Singapore Med J 1990; 31:529-38.

19. Teh BT. What molecular genetics holds for the future? Singapore Med J 2001; 42:1-2,4-5.

20. Chin R. The Internet: another facet to the paradigm shift in healthcare. Singapore Med J 2000; 41:426-9.

21. Ho GC. The evolution of positron emission tomography. Singapore Med J 2005; 46:257-8.

22. Isaac J, Lim SG. The future of liver transplantation in Singapore. Singapore Med J 2006; 47:564-5

23. Lim KD. A case of pathological gambling - its features and management. Singapore Med J 2001; 42:217-9.

24. Phua KH. The social costs of disease and the economics of prevention. Singapore Med J 2002; 43:329-30.

25. Koh NY, Koo WH. Polypharmacy in palliative care: can it be reduced? Singapore Med J 2002; 43:279-83.

26. Tan B. The evolution of sports medicine in Singapore. Singapore Med J 2013; 54:552-4.

27. Ng JH, Yeak S, Phoon N, Lo S. Cosmetic procedures among youths: a 
survey of junior college and medical students in Singapore. Singapore Med J 2014; 55:422-6.

28. Liow MH, Chin PL, Tay KJ, et al. Early experiences with robot-assisted total knee arthroplasty using the DigiMatch ${ }^{\mathrm{TM}}$ ROBODOC® surgical system. Singapore Med J 2014; 55:529-34.

29. Tambyah PA. The SARS outbreak: how many reminders do we need? Singapore Med J 2003; 44:165-7.

30. Chee YC. Heroes and heroines of the war on SARS. Singapore Med J 2003 44:221-8.

31. Tan CC. Rethinking medical education. Singapore Med J 1998; 39:273-6.

32. O'Brien AP, Arthur DG. Singapore nursing in transition: perspectives from the Alice Lee Centre for Nursing Studies, National University of Singapore. Singapore Med J 2007; 48:875-9.

33. Cheong PY. Education and training in family medicine: looking ahead. Singapore Med J 2014; 55:124-5.

34. Ng PS, Ang LP, Kandiah N. Importance of mental capacity: time for greate attention and action. Singapore Med J 2015; 56:646-8.

35. Chia HS, Ho JA, Lim BD. Pharmacist review and its impact on Singapore nursing homes. Singapore Med J 2015; 56:493-501.
36. Lee WF, Ooi CK, Phua DH, et al. The Little India riot: experience of an emergency department in Singapore. Singapore Med J 2015; 56:677-80.

37. Toh C. SMA Lecture. Impact of a free market system on medicine in Singapore. Singapore Medical Association. Singapore Med J 1997; 38:7-10.

38. Yong NK. SMA Lecture. No man is an island. Singapore Med J 1993; 34:295-7.

39. Ratnam SS. The tenth Singapore Medical Association Lecture 1977. The doctor's dilemma. Singapore Med J 1977; 18:94-9.

40. Chew $\mathrm{CH}$. "Not to be ministered unto, but to minister". Singapore Med J 1999; 40:3-8.

41. Cohen Y. SMA Lecture. Association, Profession, Adaptation. Singapore Med J 1971; 12:121-6.

42. Woo KT. Physician leadership. Singapore Med J 2007; 48:1069-73.

43. Wong HS. In search of future role models in medicine. Singapore Med J 1997; 38:459-64.

44. Nambiar RM. Professional development-in a changing world. Singapore Med I 2004; 45:551-7.

45. YC Chee. Do no harm: do thyself no harm. Singapore Med J 2005; 46: 667674. 